\title{
INVESTIGATING LEARNER AUTONOMY IN A TOEFL PREPARATION PROGRAM
}

\author{
Nurul Noviana, Priyatno Ardi \\ Sanata Dharma University \\ ms.nurulnoviana@gmail.com,priyatnoardi@usd.ac.id
}

Submitted : 2020-01-20

Accepted : 2020-03-30

\begin{abstract}
Learner autonomy is associated with the ability to take charge of students' own learning. The exercise of learner autonomy can be found in the TOEFL preparation program. TOEFL preparation program is a course that aims to assist learners in achieving the necessary TOEFL score to fulfill requirements as ELT students. The class provides learners with more opportunities to study in pre-face-to-face sessions. These opportunities are meant to give the learners a chance to exercise their English. This paper investigates the learning activities and exercise of learner autonomy in the pre-face-to-face sessions in the TOEFL preparation program. The study employed a qualitative narrative inquiry, grounded in phenomenological research. Data were collected and analyzed qualitatively by understanding the meaning of lived experiences narrated by 5 participants and observing the TOEFL class. The findings showed several extensive language activities conducted by the learners. The exercise of learner autonomy was presented in five thematic categories, namely learner autonomy as strategy, learner autonomy as perceptions, learner autonomy as behavior, learner autonomy as the interdependence of social autonomy, and experiences from learning TOEFL test preparation program in learners' lived experiences.
\end{abstract}

Keywords: learner autonomy, TOEFL preparation program, pre-face-to-face session, phenomenological research

\section{INTRODUCTION}

Currently, there is no best method to learn a language that can be applied to every individual (Pearson, 2004). Different learners learn differently because every learner has their own goals to achieve their target in learning. Benson \& Reinders (2011) supported that as a natural product of learning language, learners should associate the ideas of an individual's objectives, progress, and evaluation within the learning practice as adult learners.

The field of language teaching and learning has already shifted from conventional teacher-centered learning to learner-centered learning (Shams, 2013), in which students become the learning center and personal experiences become a part of the learning processes. This learning model allows teachers to improve classroom experiences and management systems with fewer lectures and more activities (Dang \& Robertson, 2010; Sanprasert, 2010). To connect learners with real-life experiences, any activities the learners and teachers do inside the classroom will become more vibrant if they perform them outside the classroom. Learning a language outside the classroom eventually prepares learners to use the language naturally.

Learning activities outside the class can be an alternative way that minimizes teacher centeredness. Xhaferi \& Xhaferi (2011) explained that by exploring materials before coming to the class, learners can study from new information which, in turn, can be shared or connected with a new lesson in the class. The preparations done by the learners before the class begins are 
considered pre-face-to-face sessions. Any activities in preparing the lesson to support their language learning, such as watching movies, playing games, listening to and singing songs, doing internet activities, are illustrated as daily routine activities (Chusanachoti, 2009). These activities are included in the pre-face-to-face session.

Most teachers are usually not concerned about the learning progress of their students outside the class (Pearson, 2004). In Asian contexts, this will be more complicated and problematic because students seldom explore the materials on their own will or do additional learning activities outside the classroom (Chusanachoti, 2009; Nakamura, 2008). More difficulties occur when the size of the class is too large and when there are too many learners inside the class, especially when the time allocated for learning inside the class is limited. Thus, the habits of learning outside the classroom before joining the class should be developed to increase personal responsibility in learning the language.

Thanasoulas (2000) mentioned that learners have the responsibility to learn. This responsibility assumes that learners should know how to learn by themselves to understand what they need (de Oliveira e Paiva \& de Carvalho Fidelis Braga, 2008). The responsibility of learners as autonomous learners is an important part of language learning that needs to be explored. Learners' active participation and responsibility for their learning process are necessary, especially in the field of foreign language learning (Dam, 1995 as cited in Adela, Stefánsdóttir, \& Ed, 2011). Learners need to be open to "act independently and in co-operation with others, as a socially responsible person" (Dam, 1995 as cited in Țurloiu \& Stefánsdóttir, 2011, p.10). Therefore, learning autonomously is very important, and teachers should provide proper scaffolding to help learners learn inside the class and outside the class.

To support independent learning, pre-face-to-face sessions can allow learners to learn a language outside the classroom. Chusanachoti (2009) sees this method of learning as an active behavior of an autonomous learner. It is believed that learners that practice learning out of class have more learning opportunities (Benson \& Huang, 2008; Hyland, 2004; Inozu, Sahinkarakas, \& Yumru, 2010; Pearson, 2004). In this instance, the pre-face-to-face session provides wider opportunities for language learning. Besides, the potential for individuality could be seen not only in the way students learn, but also in the way learning is applied to wider contexts (Tseng, Liou, \& Chu, 2020).

Some studies regarding learners' beliefs and preferences in out-of-class learning tend to assume that combining classroom learning and learning activities outside the classroom is the best way to place naturalistic learners (Benson \& Reinders, 2011). For that reason, the pre-faceto-face session expects EFL learners to find their learning methods and provide knowledge effectively by preparing the lesson before coming to the class. However, a study conducted by 
Ardi (2017) showed that in Indonesian contexts, fostering autonomy in EFL classes becomes a crucial way to prepare students to be involved in a democratic society. Learner autonomy is related to independent learning as it can direct an individual's potential to keep life-long learning. If the learners understand their role in learning, they will be likely not only to be aware of the importance of every lesson and learning process but also to have enough confidence in their knowledge which might be discussed in the class. A teacher should not be an authoritative figure in the class who knows that everything is right or wrong.

Studies have still neglected language learning outside the English classroom (Benson, 2001). Even though English is not a primary language in Indonesian contexts, lessons and activities that accompany pre-face-to-face sessions can be arranged before the class. Learning activities outside the class still need to be explored. Thus, this research aims to describe the learning activities and use of learner autonomy in the pre-face-to-face sessions

\section{METHOD}

This research was designed to investigate learners' lived experiences on how they exercised their learner autonomy in pre-face-to-face learning. This research employed qualitative phenomenological research which focused on investigating the phenomenon of preface-to-face sessions (Ary, Jacobs, Sorensen, \& Razavieh, 2010) based on participants' experiences. Heigham \& Crocker (2009) stated that understanding and finding out a certain phenomenon in participants' real-life experiences are the essence of phenomenological research.

The location or setting which was used in this research was the TOEFL preparation program for ELT 2011 in the $7^{\text {th }}$ semester. The program consisted of two parts: non-formal which was the learning conducted outside the class and formal classes, which was learning inside the class. The classes instructed participants to be naturalistic since they were given more independence to learn based on their target. The locus of control was relevant to the lecturer's accommodation on the learners' preparation in the pre-face-to-face session.

This research focused on 5 students in a TOEFL Preparation Program class and their out-of-class learning experiences to prepare themselves before coming to the class. The students were categorized based on the progress of the TOEFL results. The categories were as follows:

1. Participant 1 (P1) was a student who has shown significant progress and scored above 525,

2. Participant 2 (P2) was a student who has shown significant progress but received a score that was under 525 ,

3. Participant 3 (P3) was a student who prepared for the classes outside the campus and still participated in the learning process inside the classroom, and has dramatically improved their score,

4. Participant 4 (P4) was a student who scored above 550 in the beginning and she aimed to reach a score of 600 ,

5. Participant 5 (P5) was a student who scored 570 in the beginning and received the highest score when taking the TOEFL prediction test.

Field evaluation, record collection, and semi-structured interview sessions were used for collecting data. The data were analyzed based on the nature of the phenomenological research design, namely bracketing and phenomenological reduction, delineating units relevant to 
research questions, clustering unit meanings to form themes, summarizing and validating interviews, extracting general and unique themes, and making a composite summary.

\section{FINDINGS AND DISCUSSION}

\section{Learning activities conducted by the learners in the pre-face-to-face session}

The findings showed that the students performed various activities to prepare for the TOEFL test. Most of the activities were conducted after the class and outside the classroom. The results showed that the participants were autonomous learners, who could accommodate what they needed in the pre-face-to-face sessions. The students were fully equipped with the necessary skills for autonomous learning as required in the pre-face-to-face sessions.

The activities outside the class were conducted to support the lesson, especially when the students did not understand the materials. The activities vary from one participant to another. The activities done by the participants outside the class to improve their skills in the TOEFL preparation can be seen in Table 1 .

Table 1. Learners' activities in pre-face-to-face learning of TOEFL Preparation class

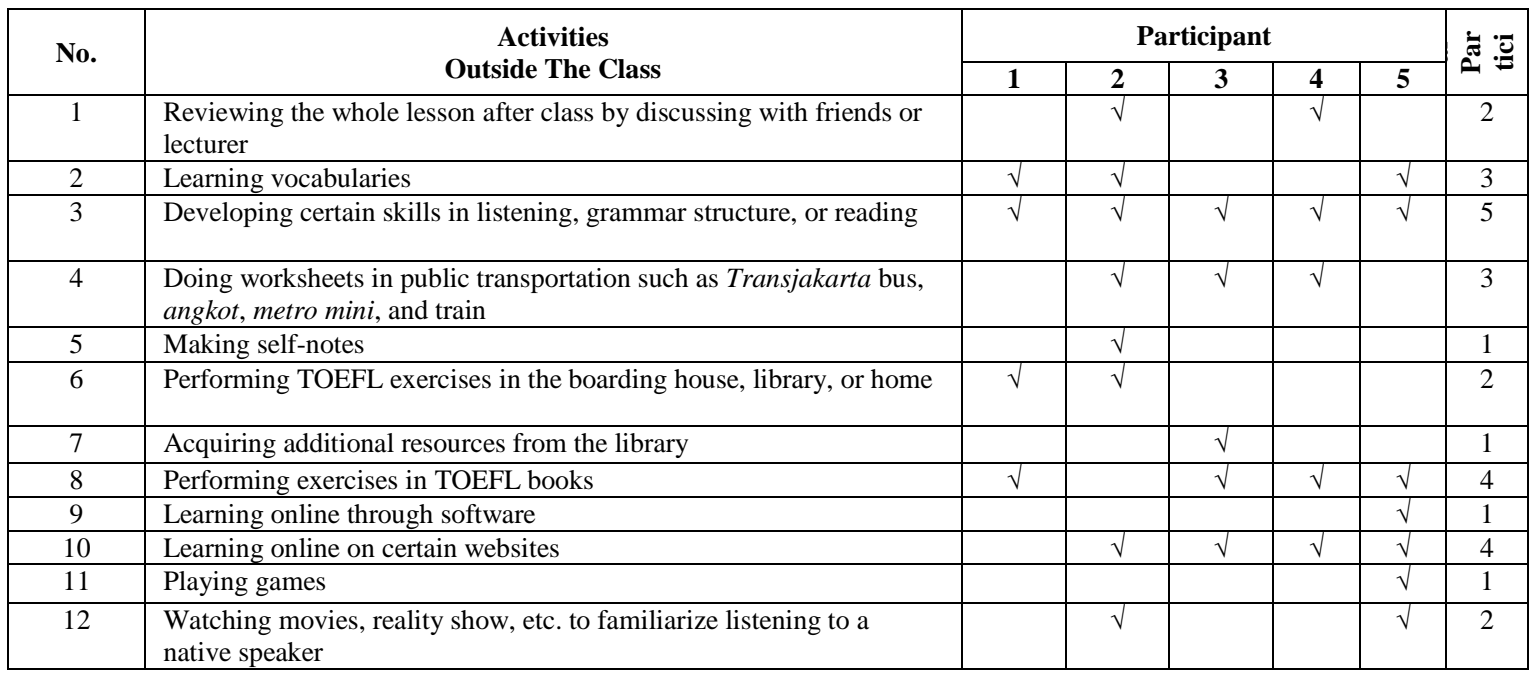

Those activities were reported as effective activities performed by the participants.

Based on the participants' experiences, they successfully achieved their target TOEFL score of higher than 525. The participants showed that the effort that helped them the most in pre-faceto-face sessions was improving their skills in listening, structure, and reading. As a result, the learners were able to pass the TOEFL test.

The second most popular activity included doing the exercises in TOEFL books and learning through websites. These activities indicated learners' interest in the pre-face-to-face session. These two activities, which were performed by several participants' outside the class, showed their willingness (Lamb, 2004) to learn the language through doing TOEFL exercises and studying to achieve the target. 
The lecturer also provided the participants with experiences to learn vocabulary and finish the worksheets by themselves. The participants were able to access and choose appropriate media or technology to learn the language (Pearson, 2004) or any other authentic materials (Neupane, 1970). This, in turn, benefitted the learners by increasing their proficiency skills in the exercise. The literature on technology-enhanced language learning has shown the power of language learning through technology. Lai \& Gu (2011) said that technology can optimize language learning outside the language classroom.

Besides, to shape their English, the participants need to incorporate English into daily life routines. In the interview, two participants preferred to watch movies, reality shows, and the like to prepare for the TOEFL preparation test and to review the whole lessons in the pre-faceto-face session. This is different from Chusanachoti (2009) who stated that learners spent more time working outside the classroom by giving them less time on homework. In this research, the participants were given more opportunities in the pre-face-to-face session. To exercise those opportunities, the learners attempted to match their TOEFL score target and provide contextual materials by watching movies. According to Pearson (2004), motivation can also influence learners' desire to end their study in an informal time, which in this case is the out-of-class learning session.

Some of the participants agreed that learning activities, such as making self-notes, finding additional exercise, learning online through certain software, and playing games, had successfully driven them to achieve the target score and learn the language well. The extensive activities were strongly connected to learners' life and environment. Lamb (2004) explained that learners covered their lack of language by doing personal exercises outside the class. Moreover, the tasks which were assigned by the lecturer directed the learners to fulfill what they had to finish. This evidence shows that the learners successfully maximized themselves in the pre-faceto-face sessions of the TOEFL preparation program. However, different participants conducted different activities, depending on their interests and weaknesses in TOEFL.

The TOEFL preparation program provided the learners with opportunities to study outside the classroom. The opportunities encouraged the learners to be more creative to find various activities that were appropriate with their interests and needs. The learning activities depended on learners' learning styles and needs. Individual learners differ in their learning habits, interests, needs, motivations, and develop various degrees of independence throughout their lives (Tumposky, 1982 as cited in Benson \& Reinders, 2011). These differences encouraged the students to study English in a more fun and interesting way. 
In doing out-of-class activities, the participants mostly employed strategies to improve their skills in listening, grammar structure and reading. The first participant used the strategies that she learned in the class. She said:

\begin{abstract}
"...I followed the instructions as like as the lecturer said in the class and the book said, for example in the short conversation part. In this part, I should keep focusing on the second speaker, not try to choose the same words as the right choice to answer, because it's a trap." (PI23-INT3 Q1)
\end{abstract}

The second participant also did the same on reading skills. She remembered what the lecturer said as the strategy in the reading section.

“...So, yesterday based on an explanation from Ms. Ades when I'm doing the exercise, I remembered what she said that I have to find the main idea..." (PII15-INT3 Q1)

The third participant had difficulties accomplishing the written structure section. As a result, she studied from another resource at home.

“...But for the skills that I learned by myself were written structure section. I bought additional exercises. I also have a book. So, I exercised my skills independently at home ... " (PIII13-INT3 Q1)

The fourth participant admitted that he was not good at structure or grammar point. He employed some strategies from his experiences in doing the TOEFL test. He said:

\begin{abstract}
"In structure, often feel what ... I do such if it so look in, oh this is but it was wrong. The method for this that I used was wrong.. And it turns out it should be right, already right, it should be read it over and over again. Then certainly will see later which one is best. Yes so, plumpness structure anyway, because I cannot remember let alone patterns difficult kinds of negative, inversion, well aware that often, or that fit prediagnostic, ehm I mean pre-diagnostic, which was yesterday, yesterday week, the second week, the given structure one of 10, and that there are three or five, if I'm not mistaken, about 3-5 was it, those were wrong because of a silly mistake. So that it was actually one "has or have" but it was not that, I realize so, this was wrong, but this actually right. When it's very easy so, as like "plural", it turns out it's just so "subject-verb agreement", the fact, the hard questions will be easier now, and the simplest questions, I'm not aware so. Laaahhh... It has so, for example, "the ocean", oceans don't use "s" so why use the? The word "ocean" it's just one, the only one so right? It turns out that because he has supposed only the ocean." (PIV6-INT3 Q1)
\end{abstract}

The fifth participant stated that his listening skill was bad. He said:

"Yah, more or less. You can see that TOEFL listening is that... it's very not clear, the sound. I don't know maybe just, I expect to use my headset so in the real TOEFL class, the real TOEFL exercise because you use your headset, you can maximize your ear, when you use the speaker then that's my difficulty in TOEFL test." (PV17-INT3 Q1)

\title{
The exercise of learner autonomy in the pre-face-to-face session
}

Based on the findings, the participants showed that they exercised learner autonomy in the preface-to-face session. The results of the interview were categorized into themes, mostly adopted from Sanprasert (2010), as in Table 2.

Table 2. Themes from learners' learning lived experiences

\begin{tabular}{c|l|l}
\hline No. & Group & $\begin{array}{l}\text { Themes } \\
\text { Theme 7: setting their own goals and how the result showed in achieving the } \\
\text { language target } \\
\text { Theme 10: planning for more exercises outside the classroom as pre-face-to- } \\
\text { face session } \\
\text { Theme 11: self-monitoring and self-evaluating on their learning }\end{array}$ \\
\hline 2. & Learner autonomy: strategy & $\begin{array}{l}\text { Theme 3: awareness of feedback importance } \\
\text { Theme 8: teacher's role from learners' point of view } \\
\text { Theme 9: lived experiences before }\end{array}$ \\
\hline 3. & Learner autonomy: behavior & $\begin{array}{l}\text { Theme 1: independence, self-directed, autonomous language learning } \\
\text { Theme 2: confidence } \\
\text { Theme 4: Contributing to materials inside the classroom to find outside as pre- } \\
\text { face-to-face session }\end{array}$ \\
\hline 4. & $\begin{array}{l}\text { Learner autonomy: interdependence or } \\
\text { social autonomy }\end{array}$ & $\begin{array}{l}\text { Theme 5: collaborative learning, learning from peers } \\
\text { Theme 6: affective support among peers }\end{array}$ \\
\hline 5. & $\begin{array}{l}\text { Experiences from learning TOEFL test } \\
\text { preparation }\end{array}$ & $\begin{array}{l}\text { Theme 12: awareness of the language } \\
\text { Theme 13: difficulties and problems in the learning }\end{array}$ \\
\hline
\end{tabular}

Out of class activities gave more opportunities for the students to do learning activities that interested them, to learn specific topics that were considered difficult, to plan the target, to 
process resource materials, and evaluate learning. In the TOEFL class context, the time to learn inside the class was limited to 100 minutes in a week while the target score of 525 was considered high. This condition forced learners to find additional information outside the class. The advent of new technologies assisted the students in learning. The data showed that technology played an important role in finding information. TV series, online games, websites, and software that supported TOEFL exercises could attract the students. These audio-visual dimensions were used to support learners' preparation and motivate them to do exercises.

The results showed that all participants exhibited the exercise of learner autonomy in pre-face-to-face sessions for the TOEFL class. Based on the interview, 13 themes have emerged. First, participants 1 and 2 articulated theme 8 (the teacher's role from the learners' point of view) to point out the strategies used in the TOEFL test. Second, participant 3 verified the importance of being confident (theme 2) with the test results, contributing to materials inside the classroom by finding them outside the classroom in the pre-face-to-face session (theme 4) in her spare time, while past experiences (theme 9) influenced her to prepare for the TOEFL test. Third, participant 4 also gave evidence that collaborative learning or learning from peers (theme 5) and affective supports among peers (theme 6) made him prepare for the TOEFL worksheets outside the class by discussing it together with friends, while self-monitoring and selfevaluating their learning (theme 11); it is stated that the difficulties and problems in the learning (theme 13) were solved by addressing and understanding their strength and weaknesses, while awareness of the language (theme 12) happened when and where the learner should learn. Fourth, participant 5 showed independent, self-directed, autonomous language learning (theme 1) and awareness of feedback importance (theme 3) by doing some exercises and pointing out the mistakes, setting his goals and how the result showed in achieving the language target (theme 3) expected him to score higher.

The categorizations showed numerous learning activities or various ways of the exercise of learner autonomy. Every learner had the capacity to learn and got the opportunity to spend their time preparing for the lesson. However, other factors, such as learners' speed in absorbing the information, different learning styles, and priority also affected how the learners used their pre-face-to-face learning opportunity. As Benson and Reinders (2011) and Soto et al (2019) explained, the learners have their learning strategies as their target learning achievement. They also planned their adaptive lessons based on their ability to accomplish the desired lesson.

The results also supported the previous research by Benson and Reinders (2011). Preface-to-face learning activities are beyond the classroom dimension categories where the language takes place so that the learners could figure out what they learned. To achieve the target of learning, the dimensions have been divided into some categories, including location, 
formality, pedagogy and control locus. Such measurements include out-of-class, out-of-school, after-school, non-formal and informal, self-instructed, non-instructed and naturalistic, independent, and autonomous self-directed learning of languages.

It is obvious to note that whether the scheduling for the pre-face-to-face session is still reasonable. The pre-face-to-face session in this research encompasses the availability to spend time outside the classroom, whether due to free time or individual interest to do so (Thanasoulas, 2000). It also happened when the participants had to finish the tasks. All participants practiced and prepared the materials in the pre-face-to-face session before class started. The pre-face-to-face session takes a role in increasing learners' prior knowledge and as an input supplier resource before they came to the class.

Any types of time, including free time to do non-academic activities, were included as pre-face-to-face time. In the context of EFL learners, Pearson (2004) studied formal or informal activities as a study setting that can be related to pre-face-to-face time to learn with or without any intention to learn outside the classroom to practice English. This pre-face-to-face time with or without any intention to learn provides the learner opportunities in mastering English skills. Learners who have a responsibility in mastering the English language have to use the language actively in both written and spoken form. Thus, in their spare time, the participants aimed to familiarize vocabularies. The learners carried out the materials directly from the class to be learned. Then, they tried to extend their learning effort outside the class as their preparation in pre-face-to-face learning. The focus to control aspects of learning situations related to others and the self were considered as social and affective strategies in which the learners' attitude towards language as an object of learning also was implied in the learning process.

Furthermore, the pre-face-to-face session accommodated cognitive, metacognitive, social and affective strategies. Cognitive and metacognitive are strongly correlated with human growth where cognitive targets are needed and meat cognitive questions are discussed as to how the cognitive is done. The metacognitive aspects included the learners' designed planning, directed attention, selective attention, self-management, self-monitoring, problem identification, and self-evaluation. Meanwhile, in social and affective situations, the learners should have social strategies which include asking questions, cooperating with others, and empathizing with others as well as possess affective strategies, such as lowering anxiety, encouragement, and controlling emotional temperature. Participants 3 and 4 asked questions and cooperated with others by discussing the materials in their pre-face-to-face session. Other participants, such as participants 2 and 5, only asked questions to the lecturer without discussing with their peers. Participant 1 did not use any of the considerations of social categories. 


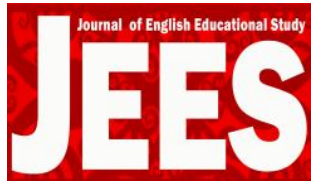

Journal of English Educational Study (JEES)

Volume 3 Issue 1 May 2020 Page 10-20

E-ISSN: 2655-0776

In affective categories, all of the participants have performed self-encouragement but did not know how to lower their anxiety. Besides, only one participant who could take emotional temperature as a learning strategy. If the learners are encouraged to reflect, evaluate their learning, consider how language proficiency develops and review their motivation and needs, they can become better independent learners. The importance of setting goals becomes the first step in how learners decide how to complete their needs in learning.

The findings indicated that not all of the participants completely used cognitive, metacognitive, social and affective strategies. This can happen because of the limited period of the TOEFL preparation program. The participants implemented metacognitive strategies in planning, directed attention, selected attention, self-management, self-monitoring, problem identification, and self-evaluation. Unfortunately, Participant 1 seemed to lack directed attention while participant 4 also lacked self-monitoring. It reflected that different learners and background knowledge can affect the missing part of this strategy.

The findings also showed that the learners were categorized not only as independent learners but also as learners who can attribute themselves as autonomous learners. The result of this research showed that the TOEFL preparation program gave more opportunities to study in pre-face-to-face sessions. The pre-face-to-face sessions are expected to expand the students' learning opportunities and make them explore new learning activities. Therefore, the various learning activities help learners to acquire language through resources that are closely related to the learners' own experiences.

\section{CONCLUSION}

This article reports a study investigating the exercise of learner autonomy in the preface-to-face session of a TOEFL preparation program. The findings showed that the learning tasks performed by the learners in the session included reading a lesson by discussion, collecting vocabulary, making self-notes, practicing some skills, doing worksheets, exploring TOEFL book exercises, photocopying other library tools, learning online through apps or websites, playing games, watching movies or reality shows to familiarize with native speakers. Students' learning activities included researching a lesson via conversation, collecting vocabulary, self-notes, practicing skills, working sheets, exploring TOEFL book exercises, photocopy of other library tools, learning online through software or websites, playing games, watching films or showing reality to the native speaker.

The study also found that the learners exercised learner autonomy in the pre-face-toface session of the TOEFL training program. The exercise of learner autonomy was reflected in the findings which were categorized into learner autonomy (strategy), learner autonomy 
(perceptions), learner autonomy (behavior), learner autonomy (interdependence or relational autonomy) and experiences from the TOEFL test preparation curriculum. The learners had access to learner control in the pre-face-to-face session by suggesting 13 topics of different learning styles, techniques, attitudes, behavior, interdependence, and TOEFL training program interactions. The other use of learner control that promoted 13 concepts was defined by perceptual, metacognitive, social and affective approaches. Such divisions were conducted in schooling by providing opportunities and resources for learners outside the classroom.

\section{REFERENCES}

Ardi, P. (2017). Promoting learner autonomy through Schoology m-learning platform in an EAP class at an Indonesian university. Teaching English with Technology, 17(2), 55-76.

Ary, D., Jacobs, L. C., Sorensen, C., \& Razavieh, A. (2010). Introduction to research in education (8th ed.). Belmont: Thomson Wadsworth.

Benson, P., \& Huang, J. (2008). Autonomy in the transition from foreign language learning to foreign language teaching. DELTA Documentacao de Estudos Em Linguistica Teorica e Aplicada, 24(SPL.ISS.), 421-439. https://doi.org/10.1590/S0102-44502008000300003

Benson, P., \& Reinders, H. (2011). Beyond the language classroom. New York: Palgrave Macmillan.

Chusanachoti, R. (2009). EFL Learning Through Language Activities. ProQuest, 1-287.

Dang, T. T., \& Robertson, M. (2010). Impacts of learning management system on learner autonomy in EFL learning. International Education Studies, 3(3), 3-11. https://doi.org/10.5539/ies.v3n3p3

de Oliveira e Paiva, V. L. M., \& de Carvalho Fidelis Braga, J. (2008). The complex nature of autonomy. DELTA Documentacao de Estudos Em Linguistica Teorica e Aplicada, 24(SPL.ISS.), 441-468.

Heigham, J., \& Crocker, R. A. (2009). Qualitative research in applied linguistics: a practical introduction. New York: Palgrave Macmillan.

Hyland, F. (2004). Learning autonomously: Contextualising out-of-class English language learning. Language Awareness, 13(3), 180-202. https://doi.org/10.1080/09658410408667094

Inozu, J., Sahinkarakas, S., \& Yumru, H. (2010). The nature of language learning experiences beyond the classroom and its learning outcomes. US-China Foreign Language, 8(1), 14$22 . \quad$ Retrieved from https://s3.amazonaws.com/academia.edu.documents/36449541/the_nature_of_language_le arning.pdf?AWSAccessKeyId=AKIAIWOWYYGZ2Y53UL3A\&Expires=1531767036\&S ignature=fdeAflW5gDrnxLA26zc2B2onZoE\%3D\&response-contentdisposition=inline\%3B filename\%3DThe_nature_of_la

Lai, C., \& Gu, M. (2011). Self-regulated out-of-class language learning with technology. Computer Assisted Language Learning, 24(4), 317-335. https://doi.org/10.1080/09588221.2011.568417

Lamb, M. (2004). "It depends on the students themselves": Independent language learning at an Indonesian state school. Language, Culture and Curriculum, 17(3), 229-245. https://doi.org/10.1080/07908310408666695

Nakamura, I. (2008). Understanding how teacher and student talk with each other: An exploration of how "repair" displays the co-management of talk-in-interaction. Language Teaching Research, 12(2), 265-283. https://doi.org/10.1177/1362168807086295

Neupane, M. (1970). Learner Autonomy: Concept and Considerations. Journal of NELTA, 15(1-2), 114-120. https://doi.org/10.3126/nelta.v15i1-2.4617

Pearson, N. (2004). The idiosyncrasies of out-of-class language learning : A study of mainland 
Chinese students studying English at tertiary level in New Zealand. Proceedings of the Independent Learning Conference 2003, (September), 1-12.

Sanprasert, N. (2010). The application of a course management system to enhance autonomy in learning English as a foreign language. System, 38, 109-123. https://doi.org/10.1016/j.system.2009.12.010

Shams, I. E. (2013). Hybrid learning and Iranian EFL learners' autonomy in vocabulary learning. Procedia - Social and Behavioral Sciences, 93, 1587-1592. https://doi.org/10.1016/j.sbspro.2013.10.086

Soto, C., Gutiérrez de Blume, A. P., Jacovina, M., McNamara, D., Benson, N., \& Riffo, B. (2019). Reading comprehension and metacognition: The importance of inferential skills. Cogent Education, 6(1), 1-20. https://doi.org/10.1080/2331186x.2019.1565067

Thanasoulas, D. (2000). What is Learner Autonomy and How Can It Be Fostered. The Internet TESL Journal, Vol. 6, pp. 37-48. Retrieved from http://iteslj.org/Articles/ThanasoulasAutonomy.html

Tseng, W. T., Liou, H. J., \& Chu, H. C. (2020). Vocabulary learning in virtual environments: Learner autonomy and collaboration. System, 88, 102190. https://doi.org/10.1016/j.system.2019.102190

Țurloiu, A., \& Stefánsdóttir, Í. S. (2011). Learner autonomy theoretical and practical information for language teachers. https://skemman.is/bitstream/1946/7668/1/B.Ed.\%20loka\%C3\%BAtg\%C3\%A1fa.pdf

Xhaferi, B., \& Xhaferi, G. (2011). Developing learner autonomy in higher education in Macedonia. Procedia - Social and Behavioral Sciences, 11, 150-154. https://doi.org/10.1016/j.sbspro.2011.01.051 